\title{
MANUAL DEL PRACTICANTE Y DE PARTOS NORMALES (1906): CONTENIDO Y CURIOSIDADES.
}

\author{
Antonio Manuel Ballesteros Álvaro \\ Diplomado Universitario en Enfermería. \\ Centro de Salud de Carrión de los Condes (Palencia)
}

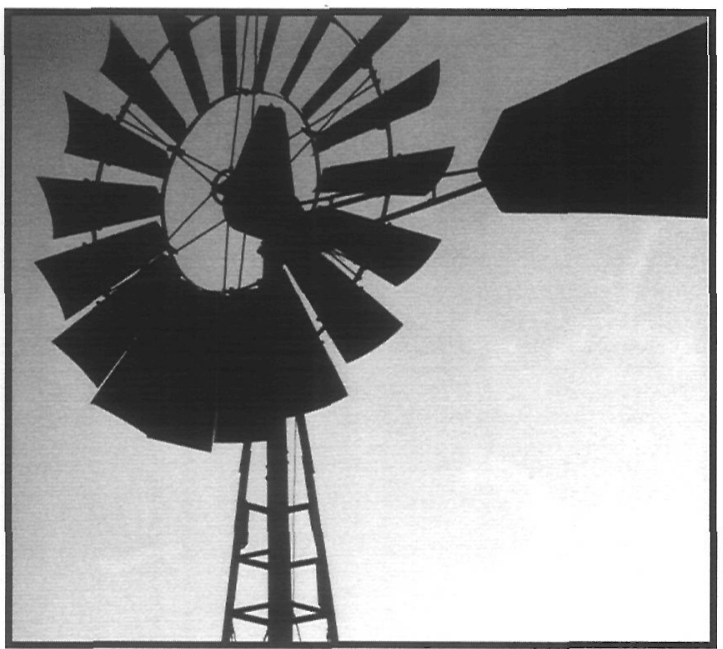

A MANUAL FOR NURSES AND FOR NORMAL DELIVERIES. (1906): CONTENTS AND INTERESTING CUSTOMS (1)

\section{SUMMARY:}

I n 1906, the doctor Emilio A. García Sierra publishes the book: "A Manual for nurses and normal deliveries", according to the study programme approved by the Law of 1902. Anatomy, minor surgery, births... are studied in the manual, according to the tasks allowed to be performed by nurses at the begining of the 20th century. The manual mainly shows bandage techniques, bleedings, catheterization, dressings, vaccination, births... What we may consider today as proper care, will be assigned to "less qualified hands", as hospital aides. The browsing in manuals like this allow us to do a follow up on the way nursing has evolved especially in theoretical education, functions, responsibilites and some other aspects which will contribute to analyse the origins and velopment of our profession.
Key words: nursing, hospital aide, midwife, History of Nursing, Education manuals.

(1) Note from the translator: In Spain, the term "Practicante" was given to a full quilified nurse years ago (SRN) nowadays.

The term "nurse" at the time, was given to a not fully qualified nurse. It could be compared to SEN

\section{RESUMEN:}

П $\mathrm{n}$ el año 1906, el médico D. Emilio A. $\checkmark$ García Sierra publica el libro "Manual del 1 Practicante y de Partos Normales" conforme al programa aprobado en el año 1902. Este manual desarrolla, a lo largo de sus páginas, temas como anatomía, cirugía menor, partos, etc. de acuerdo a las atribuciones que tenían a comienzos del siglo XX los practicantes. Así pues este manual refleja, ante todo, técnicas como los vendajes, sangrías, sondajes, curas, vacunaciones, partos,...; los cuidados propiamente dichos quedaban relegados para que un personal "menos cualificado", cual eran las enfermeras, los realizaran. El estudio de manuales como este nos permiten pues conocer como ha evolucionado la enfermería en cuanto a formación académica, funciones, responsabilidades y otra serie de aspectos que nos ayudaran a elaborar el pasado de nuestra profesión.

Palabras Clave: Enfermería, Practicante, Matrona, Historia de la Enfermería, Manuales de formación.

\section{INTRODUCCIÓN Y JUSTIFICACIÓN.}

Desde los albores de la civilización, y en España con documentos escritos desde el s. XII, se tiene constancia de una clara actividad de enfermería, sobre todo en hospitales y monasterios. 
Posteriormente y durante años, la actividad sanitaria estuvo regulada por el Tribunal de Protomédicos que tenía tres jurisdicciones: protomedicato, protocirujanato y protobarberato. Este último ya funcionaba en el año 1500 (pragmática de los Reyes Católicos de 9 de Abril de 1500).

Con posterioridad fueron la Junta de Medicina, Cirugía y Farmacia, primero, y la Junta Superior de Sanidad, después, las encargadas de reglamentar las actividades de las profesiones sanitarias. En 1780 se suprime el protobarberato cuyos fines eran "anexo al de cirujano y sangrador". La figura del cirujano sangrador se oficializaría más tarde (R.O. de 16-VI- 1827) y estaba ligada a la figura de barbero y dentista.

La partera o comadrona tiene también un origen muy antiguo, siendo normalmente una mujer del pueblo con un conocimiento empírico sobre el cuidado de la madre y del recién nacido. Ya en el siglo XVI, hay documentos en los que se plasma la necesidad de formar correctamente a estas mujeres. Fruto de ello es la impresión en 1541, en Mallorca, del Manual Carbó para matronas considerado, así mismo, como el primer manual de enfermería escrito en España y el segundo libro de obstetricia en lengua vulgar del mundo.

También se escribe, en 1658, el "Manual de enfermería de Simón López".

Pero no será hasta el 9 de Septiembre de 1857, con la publicación de la Ley de Instrucción Pública o Ley Moyano, cuando se oficializan las carreras de Practicante y Matrona, derogándose las anteriores disposiciones que permitían la formación de cirujanos menores o ministrantes y parteras (Art. 40 y 41 de la Ley Moyano). Posteriormente, en 1860 y 1861 se publicarán los primer Reglamentos sobre la enseñanza de Practicantes.

En 1896, el Dr. Federico Rubio Galí crea la primera escuela de enfermeras (Santa Isabel de Hungría), cuya idea concibió en Inglaterra mientras se encontraba en calidad de embajador de España (aunque no será hasta 1915 cuando se apruebe el primer programa para la formación de enfermeras a petición de la congregación de las Siervas de María, Ministras de los enfermos.)

Tras la publicación de distintas Reales Ordenes, que van poco a poco configurando el esqueleto de estas dos profesiones llegamos al año 1902; ese año, el Conde de Romanones firma la Real Orden de 13 de Mayo de 1902 (publicada en la Gaceta de Madrid el 3-VI-1902) y en la que se aprueba el Programa de estudios elaborado por la Facultad de Medicina de la Universidad Central para el estudio de la Carrera de Practicante. Este programa, así como el desarrollo de los distintos temas que lo componen son el eje central del libro "Manual del Practicante y de Partos Normales", cuyo contenido y curiosidades son el motivo de este estudio.

Se pretende pues, dar a conocer el contenido de este manual, con casi un siglo de antigüedad, para entender como a través de este manual y de otros como él, es posible conocer como fue evolucionando la profesión, las relaciones existentes en cada momento con otros profesionales sanitarios, las distintas funciones que podíamos desempeñar en función de los temas incluidos en estos libros; en fin, conocer lo que hemos sido para entender mejor lo que somos.

\section{EL MANUAL DEL PRACTICANTE Y DE PARTOS NORMALES (1906)}

El "Manual del Practicante y de Partos Normales" (en adelante el Manual), es un libro de 1906, editado en Valencia por Pubul y Morales y escrito por el médico D. Emilio A. García-Sierra. Consta de 658 páginas ( 78 capítulos), a lo largo de las cuales, el autor va desarrollando los distintos temas de que constaba el programa para el estudio de la carrera de Practicante del año 1902 (R. O. de 13-V-1902, que aparece en las primeras páginas del Manual).

El Manual se divide en: introducción, anatomía, técnicas de cirugía menor, partos y nociones de medicina y cirugía de urgencia. Consta el manual, además, de 56 láminas explicativas.

Capítulo I de las relaciones del Practicante con el Médico y el Farmacéutico y de las condiciones morales y científicas que deben adornarle. El Capítulo I dice así: "El practicante de Medicina es el encargado de ejecutar en la clínica oficial o particular las prescripciones que ordena un profesor médico, siendo, por tanto, responsable de su técnica, pero no de su finalidad (...) será instruido, obe- 
diente, honrado y virtuoso en grado sumo, debe respeto y sumisión absoluta al director de la Clínica en primer término y a los profesores Médicos Ayudantes de la misma en caso de haberlos (...) Realizará, con arreglo a su leal saber y mayor perfeccionamiento posible, cuantas operaciones se le encomienden, sin discutirlas ni alterarlas(...) lo primero por que no debe juzgar de lo que no conoce a fondo y lo segundo (...) por que puede acarrear al enfermo perjuicios de consideración y hasta la muerte misma(...)Cuidará muy especialmente de no confiar a nadie lo que debe realizar por sí; hace menosprecio de su profesión el Practicante que confía a un criado o enfermero la realización...de sus deberes...". "Con los enfermos mostrará un cariño superior a toda ponderación (...) El enfermo es siempre(...) un ser sagrado que está a salvo de todas las pequeñeces de nuestros deseos. (...) Todos los actos médicos son susceptibles de realizarse sin herir en lo más mínimo el pudor y el decoro más delicados; el Practicante que por curiosidad o fines aún más bajos, cometiese algunos actos que se aparten de la seriedad y honradez que deben ser norma de su conducta, es indigno de llevar un título académico ni de ser auxiliar de la más sagrada de las profesiones". En resumen, "la mejor norma que puede tener un practicante en sus relaciones con el Médico, es considerarle en todos los actos profesionales como corresponde a la superior categoría oficial que por su título disfruta...". Además de todo lo dicho hasta ahora, el practicante debía: “... ejercer su profesión con prudencia y paciencia sin salirse de su esfera y con el ideal de quien ejecuta la más meritoria obra de misericordia: aliviar al que padece. Las condiciones científicas son: instrucción teórico-práctica, aptitud, entusiasmo profesional y pericia (...) para enaltecer su carrera hasta el límite máximo, empleando el mejor de los medios, que es elevar el nivel intelectual y moral de cada uno de los que pertenecen a ella. El Practicante, en fin, ha de tener cierto grado de pericia para que uniéndose la bondad del mandato médico con lo primoroso de su ejecución resulte el mayor beneficio para el enfermo". No considero necesario hacer más comentarios pues todo queda dicho.

Del Capítulo II al XVII nociones básicas de anatomía. Del Capítulo II al XVII (pág. 7 a 163) se dan unas nociones básicas de anatomía que deben ser irrenunciablemente conocidas por el Practicante para que no ocurra que "...en lugar de aplicar un revulsivo en una región lo aplique en otra...", son por tanto estas "...materias de inexcusable y absoluto conocimiento por ser de las más importantes de la carrera".

Vendajes e inmovilización de fracturas. En cuanto a los Vendajes, tras una minuciosa descripción de los distintos tipos según Gerdy (simples, compuestos y mecánicos, divididos a su vez todos en 17 categorías), se nos explica como preparar una venda; Tengamos en cuenta que en la época las gasas venían en rollos de "...50 o más metros de larga por 60 o $70 \mathrm{~cm}$. de ancha." Se explica pues como debe cortarse y enrollarse una venda para su aplicación. Posteriormente vienen recogidos los distintos tipos de vendaje según la zona corporal a inmovilizar (circulares, oblicuos, espirales, cruzados, en 8 de guarismo...). Otro tipo de vendajes eran los realizados con pañuelos, ideados por Matías Mayor ocupan el capítulo XIX y "...su importancia en medicina es grande, sobre todo en caso de urgencia...". En cuanto a los vendajes mecánicos se recogen como tales a la camisa de fuerza, el corsé (del que nos ocuparemos más adelante), los bragueros, los pesarios,...

El Capítulo XXIII y siguientes nos hablan de las fracturas, su reducción e inmovilización con férulas enyesadas o silicatadas.

La medicación tópica. De los Capítulos XXV al XXIX viene recogida la medicación tópica, que puede ser sólida, líquida o gaseosa. Las distintas variedades que encontramos entre otras, son: las fricciones, unturas, embrocaciones, fomentos, cataplasmas, cáusticos, emplastos y medicación tópica refrigerante, baños, etc... Las pulverizaciones, inhalaciones, fumigaciones, colutorios, gargarismos, enemas, inyecciones, supositorios y candelillas (supositorios uretrales) e instilaciones forman parte del resto de aplicaciones tópicas a disposición de los Practicantes de comienzos del siglo XX.

El instrumental quirúrgico del Practicante. El Capítulo XXX dedicado al instrumental quirúrgico del Practicante comienza dando unas nociones de asepsia: “...Todos deberán conservarse en el mejor estado de limpieza y desinfección, pues por ellos pueden transmitirse sin este requisito multitud de 
enfermedades contagiosas. Antes de usarles deberán hervirse con carbonato potásico, no metiéndoles nunca en disoluciones de sublimado, sino que una vez hervidos se pondrán en un recipiente con una débil solución fenicada al uno o dos por ciento, mientras dure su empleo, y no volviéndoles a poner en la cartera hasta que no queden perfectamente secos." Este instrumental quirúrgico estaba formado por: Bisturí, lancetas (de lengua de serpiente, grano de avena y grano de cebada), tijeras (rectas y curvas), pinzas (de disección, de curar y de hemostasia), estilete, sonda acanalada, porta lechinos, separadores, tenáculo, porta cáusticos, espátula, aguijas de sutura, jeringa de curas, jeringas para inyecciones hipodérmicas, cucharilla de Volkman, sonda uretral (podía ser metálica o de goma o caucho), trocar y cauterios.

Las curas quirúrgicas. El Capítulo XXXI, dedicado a las curas quirúrgicas, las divide en secas y húmedas, y los medios utilizados para realizarlas son: el algodón, las gasas, el silk o protectivo (una especie de hule verde engomado), el makintoch (una tela impermeable de caucho), los tubos de drenaje (de goma o metal), los hilos de sutura (seda, catgut, crin e hilo de plata), agua hervida y esterilizada. En cuanto a los antisépticos, el ácido fénico, el yodoformo, el timol, el cloruro de zinc, el alcohol alcanforado, el subnitrato de bismuto, el ácido bórico, el permanganato potásico y el salol, cada uno de ellos con sus específicas utilidades y presentaciones, así como sus riesgos y efectos secundarios.

El capítulo XXXII dedicado a las suturas nos explica los distintos tipos (sutura entrecortada, ensortijada y enclavijada) así como su realización.

El capítulo XXXIII habla de las reglas generales para practicar las curas: "En ningún caso ha de provar mejor el práctico la diferencia que existe entre un hombre de ciencia y el que no lo es, que el realizar una cura.". Tras limpiar y fumigar, el practicante, la sala de curas o de operaciones, esterilizará todo el material "...cociendo todo lo metálico en agua hervida con carbonato potásico y aparte las sedas y agujas;". Tras la preparación de todo el material, incluido las ropas de quirófano se prepara al enfermo y por último se procede al lavado de manos: "...desnudos los brazos, se lavan especialmente las manos con agua caliente, jabón y cepillo, restregándose bien y cuidando preferentemente las uñas; después con alcohol para quitar la grasa y por último con una solución de sublimado al 2 por 1000." Una vez realizada la cura, ésta se renovará: "...por abundante hemorragia, por que el apósito comprima demasiado, por que la cura esté muy sucia o por causa general (fiebre...). En los tres primeros casos el practicante estando sólo debe renovarla, aunque si puede tomará consejo; en el último lo necesita sin remedio, pues él no sabrá investigar la causa."

En el capítulo XXXVII tienen su espacio las sangrías, técnica “...cuya precisión clínica nunca puede hacerla el Practicante sino el Médico, a éste incumbe indicarla, como a aquel realizarla, por lo que se le ha 1lamado cirujano-sangrador." Una de las técnicas explicadas es el uso de las sanguijuelas.

Las Vacunas. El Capítulo XL dedicado a las vacunas nos explica como se obtenía y aplicaba la vacuna de la viruela, para lo cual en los hospitales, casa de socorro o centros de vacunación tenía que haber terneras para tomar directamente de ellas la "linfa-vacuna"; "para ello se rasura y desinfecta el vientre del animal y se practican escarificaciones en gran extensión con el contenido de las pústulas de cow-pox, apareciendo al cabo de seis u ocho días las pústulas de vacuna, de donde se toma para las inoculaciones humanas en tubos (viales) mezclada generalmente con glicerina.... Se aconseja vacunar a las niñas en las piernas o muslos, por evitar lleven luego en los brazos cuando mujeres, señales que según ellas están reñidas con la estéti$\mathrm{ca}(. .$.$) La preocupación del vulgo de que en tiempo$ de viruela no debe vacunarse, por que revuelve los humores, según frase de comadres y curanderos, es absolutamente falsa."

A la hora de poner una inyección, "la punción de un nervio, arteria o vena, debe evitarse conociendo anatómicamente la región; pero si por ligereza del práctico o anomalía en la dirección de dichos órganos ocurriese tan sensible accidente y le ocurriese a un practicante, deberá poner la inyección en otra parte y el sitio traumatizado tratarle(...)En todo caso, avísese al Médico."

Los sondajes. El Capítulo XLIII está dedicado, entre otras materias, a los sondajes vesicales. Como ya hemos indicado se podían realizar con sonda metálica o de caucho. En el hombre es "más 
complicado y difícil (...)y puede realizarse por el procedimiento ordinario o por el conocido con el nombre de vuelta de maestro.". Puesto que el sondaje en el hombre no difería en gran medida de cómo se realiza en la actualidad, pasaré a transcribir el sondaje femenino: "El sondaje en la mujer debe practicarse, a ser posible, sin descubrirla, es decir, bajo los vestidos, para lo cual, guiado el pico de la sonda por el dedo índice izquierdo, se levanta el clítoris y recorriendo un poco hacia abajo la línea media, el tubérculo uretral sirve de guía para introducir la sonda. No teniendo gran seguridad, aconsejo a los Practicantes limítense en lo posible usar este procedimiento que entonces va seguido de tanteos, poco conciliables con el pudor de la enferma y sujeto a suposiciones falsas, pero molestas, para el práctico." Para la sujeción de la sonda, una vez colocada, se usaban 4 sistemas, uno de los cuales consiste en atar la sonda "...a los pelos más inmediatos a la raíz del miembro." De las mujeres no se especifica nada, hemos de suponer que el sistema sería muy similar.

La anestesia. Ocupa el capítulo XLIV; Para realizarla se usaba el cloroformo o el éter. El encargado de llevarla a cabo era el Practicante, aunque no de indicarla. Además tenía que ocuparse de vigilar el estado del paciente durante la intervención, para lo cual debía de vigilar el pulso, constantemente, así como la respiración, el reflejo oculo-parpebral y el estado de la pupila. Otro tipo de anestesia era la raquicocainización, o lo que es lo mismo inyectar cocaina al $1 \%$ en el raquis y previamente calentada a $37^{\circ} \mathrm{C}$.

Partos Normales. Ocupan desde el Capítulo XLVII y hasta el LXXVII. En una primera parte se hace un estudio anatómico detallado del aparato reproductor y genital femenino, para posteriormente pasar al estudio del feto. A continuación se analiza el diagnóstico del embarazo, con signos probables y signos ciertos. Entre los probables se encuentra la desaparición de la menstruación, las modificaciones en el aparato genital y alteraciones digestivas, para terminar por decir que "La radiografía y la radioscopia han de resolver seguramente el diagnóstico precoz del embarazo.". En cuanto a los signos ciertos serían el latido y los movimientos fetales. Seguidamente se habla de la higiene del embarazo "...para lograr que la mujer embarazada desempeñe, sin tropiezos morbosos, la más trascendental de sus funciones: la maternidad.". Se habla sobre la comida, la bebida, el ejercicio, el ocio, el trabajo, las relaciones sexuales y del vestido. Aquí se desaconseja sin paliativos el uso del corsé: “Esta prenda, más hija de la vanidad que de la verdadera estética, dificulta la respiración, comprimiendo el pecho y el vientre de la madre y aprisionando a la criatura e impidiendo su desarrollo. Por este mecanismo se ha producido a veces el aborto o el nacimiento de un ser deforme, de cuya deformidad o muerte es culpable quien se preocupa más de su esbeltez que de su maternidad." En su lugar podría usarse un justillo, pero "...lo vulgar de su conocimiento nos impide describirlo".

"Durante el último mes de embarazo, deben practicarse a diario, fricciones en los pezones con agua y ron o con vino aromático, para curtir la piel y evitar la formación ulterior de grietas."

Por último el parto, del que se da una amplia descripción en cuanto a presentaciones y posiciones fetales así como la forma de enfrentarse a ellas; así mismo se hace referencia a la conducta del Practicante o Matrona en el parto además de su comportamiento con respecto a la madre y al nuevo ser, cuidados que se han de tener en el alumbramiento, etcétera... para terminar diciendo: “¿Puede una mujer parir sin dolor? Las modernísimas experiencias hechas a propósito de la raquianestesia, con la cocaína y sus derivados, permite contestar afirmativamente a esta pregunta, cuya aplicación a la práctica no se hará esperar."

Las condiciones que debe reunir una buena nodriza ponen fin a los capítulos dedicados al embarazo, parto y lactancia.

Nociones de Medicina y Cirugía de Urgencia: Constituyen los últimos capítulos del manual, y en ellos se tratan distintas enfermedades y síndromes de forma somera, simplemente para que el Practicante las conociera.

\section{CONCLUSIONES}

El Estudio de los manuales para la formación de practicantes, matronas o enfermeras es un método muy útil a la hora de ver y entender la evolución de la profesión. 
Las funciones de los Practicantes a comienzos del s. XX eran fundamentalmente técnicas de ahí que en todo el manual no existan prácticamente temas relacionados con los cuidados, dejándose éstos en manos de las enfermeras. Queda además bastante claro la superior categoría de que gozaban estos Practicantes frente a las enfermeras ("hace menosprecio de su profesión el Practicante que confía a un criado o enfermero la realización...de sus deberes...".); de ahí los posteriores conflictos que surgieron cuando se unificó bajo el título de ATS a estas tres profesiones; los practicantes no estaban de acuerdo con esa homologación pues se consideraban académica, profesional y socialmente superiores a las enfermeras.

Por medio de los temas que aparecen en este manual, se intuyen las funciones que podían desempeñar estos profesionales. Dentro de estas atribuciones han estado la de dentista, administración y vigilancia de la anestesia general, asistencia a partos, cirugía menor,... muchas de ellas perdidas hace tiempo y otras en los últimos años.

Se percibe también la enorme evolución técnica y científica acontecida en los temas relacionados con la salud, pero no deja de sorprendernos como aspectos que creíamos recientes (anestesia epidural, higiene en el embarazo,...) tienen su origen muchos años atrás.

Por último animar a las personas que tengan acceso a manuales de este tipo a que les den a conocer, pues con toda esta información podremos conocer más a fondo el pasado de nuestra profesión.

\section{BIBLIOGRAFÍA}

- Pinar García, M.E., Hernández Martín F. (1994). Orígenes de la enfermería española: ¿Practicantes y enfermeras, una misma profesión?. Vol. XLVII Nº.1098. Páginas 69-72

- Chamizo Vega, C., Ballesteros Álvaro, A.M., Magdalena Fernández, M., Cotiello Cueria, Y. (1995). Historia de la enfermería española: su evolución normativa (1857-1977). II Jornadas de Documentación científica y cuidados de la Salud, Granada.

- Siles González, J.(1999). Historia de la Enfermería. Vol. II. Edita Consejo de Enfermería de la Comunidad Valenciana. Páginas 234-251

- Gallego Caminero, G., Ferrer de San Jordi, P.; Ponsell, E.; Bover, A.; Mulet i Ferre, J.M. (1995). El manual Carbó para las matronas del siglo XVI. Rev. Index de Enfermería. primavera-verano: IV (12-13):1996

- García Martínez, M.J.; García Martínez, A.C. (1998). La enseñanza de la enfermería en la España del s. XVII. El manual de enfermería de Simón López. Cultura de los cuidados, enerojunio; Año II (3):15-23.

- Martín Hernández, F.; Delgado Marchante, A.; Pinar García, M.E.; Villahoz Márquez, M.C.: (1994). Orígenes modernos de la enfermería española: primera escuela de enfermería en España, 1896. JANO. Vol. XLVII No. 1098. Páginas 55-57

- Rodríguez García, A.R.(1994). Nueva profesión de enfermeras. La noticia: 1915. JANO . Vol. XLVII No 1098. Pág. 59-64

- Herrera Rodríguez, F. (1995). El manual de enfermería de Manuel Usandizaga (1938). Qalat Chábir, sept. III (83): 101-105

- Herrera Rodríguez ,F.(1997). Un manual para la formación de las comadronas españolas (1929). Cultura de los Cuidados. Enero -junio; Año 1 (1): 37-42.

- Martínez Argüelles, M. A. (1995). La enfermería en la Psiquiatría. Análisis de un libro de texto. II Jornadas de documentación científica y cuidados de la salud. Granada.

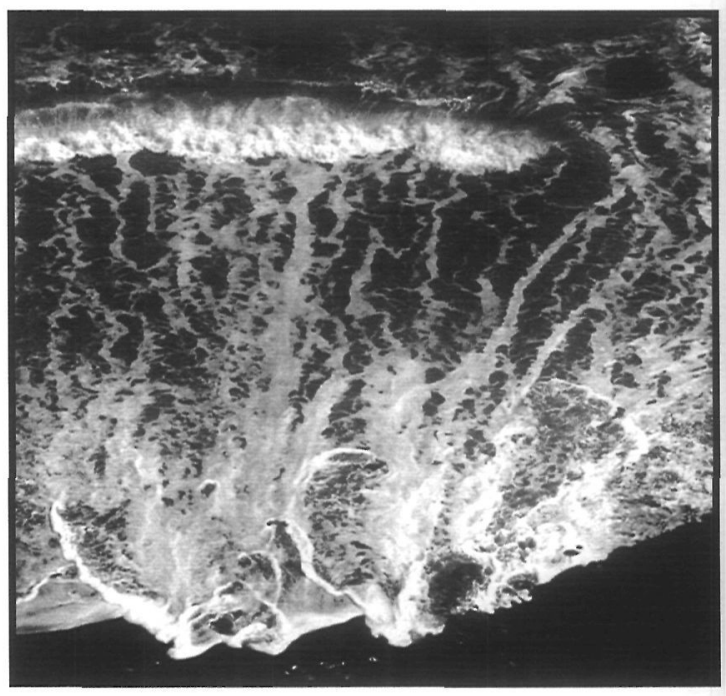

